\title{
Literatura y autoría en el cine mexicano
}

\author{
Literature and authorship in Mexican cinema
}

Literatura e autoria no cinema mexicano

\section{Maricruz Castro Ricalde}

TECNOLÓGICO DE MONTERREY, MÉXICO

Profesora investigadora del Tecnológico de Monterrey. Doctora en

Letras Modernas por la Universidad Iberoamericana (México).

Ha publicado una decena de libros de autoría individual y en

coautoría. Algunos de ellos son: El cine mexicano se impone.

Mercados internacionales y penetración cultural en la edad dorada

(con Robert McKee Irwin, UNAM, 2011); Global Mexican Cinema.

It's Golden Age (con Robert McKee Irwin, British Film Institute,

Palgrave Macmillan, 2013); Las voces del deseo. Género y literatura

en el Valle de Toluca (Gobierno del Estado de México, 2014). Sus dos

últimas publicaciones son: "Ninón Sevilla, el Caribe y la publicidad

gráfica de la edad de oro" (Hispania, 2017); y "Cecilia Pego:

novela gráfica, violencias y neocolonización" (Bulletin of Hispanic

Studies, 2019). Correo electrónico: maricruz.castro@itesm.mx

Artículo de investigación

Texto derivado de una investigación más amplia sobre los vínculos intertextuales que el cine mexicano guarda con la literatura, la gráfica popular y la música.

Documento accesible en línea desde la siguiente dirección: http://revistas.javeriana.edu.co

doi:10.11144/Javeriana.cl22-44.lacm 


\section{Resumen}

Las relaciones entre el cine mexicano y sus narradores, si bien fueron especialmente intensas durante la edad de oro, nunca dejaron de estar presentes. De ello da fe la continua existencia de obras literarias adaptadas, la relevancia de ciertos escritores que aportaban argumentos y se ofrecían como un ingrediente persuasivo para el público espectador. En este artículo deseo presentar, a través del análisis de algunos casos, la transformación de la figura del autor literario como elemento de atracción para la taquilla y las repercusiones de tales cambios.

Palabras clave: adaptación cinematográfica; autoría; cine mexicano; literatura mexicana

\section{Abstract}

The relations between the Mexican cinema and its narrators, although they were especially intense during the golden age, never ceased to be present. This is confirmed by the continued existence of adapted literary works, the relevance of certain writers who provided stories and were offered as a persuasive ingredient for the audience. In this article I wish to present, through the analysis of some cases, the transformation of the figure of the literary author as an element of attraction for the box office and the repercussions of such changes.

Keywords: film adaptation; authorship; Mexican cinema; Mexican Literature

\section{Resumo}

As relações entre o cinema mexicano e seus narradores, embora fossem especialmente intensas durante a idade de Ouro, nunca deixaram de estarem presentes. Isto é atestado pela existência continuada de obras literárias adaptadas e a relevância de certos escritores que contribuíram com argumentos e ofereciam-se como ingrediente persuasivo para o público espectador. Neste artigo desejo apresentar, através da análise de alguns casos, a transformação da figura do autor literário como elemento de atração para a bilheteria e as repercussões de tais mudanças.

Palavras-chave: adaptação cinematográfica; autoria; cinema mexicano; literatura mexicana

Cómo citar este artículo:

Castro Ricalde, Maricruz. "Literatura y autoría en el cine mexicano". Cuadernos de

Literatura 22.44 (2018): 159-179. https://doi.org/10.11144/Javeriana.cl22-44.lacm 
José Emilio Pacheco contaba una anécdota sobre el célebre escritor Federico Gamboa, quien presumía su condición de mantenido: "Pues así como me ven de decente y respetable, vivo de una mujer de la calle, mi Santa" y la completaba con la respuesta de José Rubén Romero: "Pues yo le gano, don Federico, pues yo vivo de mi Pito" (aludiendo a otra famosa novela, La vida inútil de Pito Pérez) (citado en Vázquez Mantecón 39). Este jocoso intercambio ilustra las ventajas económicas que hasta mediados del siglo veinte podían reportar tanto las ventas de algunas novelas, cuyas reediciones parecían no tener fin, hasta las ganancias que reportaban por los derechos de adaptación cinematográfica. ${ }^{1}$ Los textos literarios de gran aceptación en México se erigieron en un poderoso argumento de ventas para las obras adaptadas al cine que, en la década de los años treinta del siglo XX, apenas comenzaba a constituirse como una industria.

El propósito de las siguientes líneas es reflexionar, en un momento inicial, en el prestigio de la autoría literaria en la primera mitad de la centuria pasada, el cual se extendió a otras manifestaciones artísticas. En concreto, me interesa profundizar en el impacto que tuvo en el cine mexicano y cómo este se aprovechaba del éxito previo de las narraciones firmadas por plumas igualmente conocidas. Para ello vincularé la novela Santa (1903), con la versión cinematográfica de Antonio Moreno (1932). En un segundo apartado, compararé las estrategias de difusión de ese periodo con las del nuevo siglo, a fin de mostrar cómo se ha modificado la percepción del escritor literario y consolidado el cine como expresión artística. La asimetría axiológica que existía hace décadas ha desaparecido en el espectro de la recepción cinematográfica, y, en cambio, el tránsito a la pantalla grande parece impactar más fuertemente en el texto literario y concederle una oportunidad renovada para encontrar nuevos lectores.

1 Valorado como un "best seller" por el propio Pacheco, dada la aceptación de la novela desde su primera edición, Santa (1903) había vendido cerca 60 mil ejemplares, poco después del fallecimiento de su autor en 1939 (216). Gamboa recibió cinco mil pesos por los derechos para llevarla al cine por segunda vez y acordó obtener el cinco por ciento de las utilidades. Dos años después de su estreno, había producido 700 mil pesos (García Riera 50). Santa ha sido adaptada en forma explícita a la pantalla grande, en cuatro ocasiones y, en 1978, se grabó en México una telenovela que conservaba el título original (puedo citar otros casos en los que la historia es la misma, pero se optó por asignarle un nombre diferente al producto final). Por su parte, la obra de Romero fue llevada tres veces al cine y también se rodó una secuela; todo ello, en menos de veinte años, desde la fecha en que se publicó por primera vez (1938). La coincidencia temporal de la edad de oro del cine mexicano con las adaptaciones sucesivas de estas novelas revela la percepción de que se requería una sinergia entre ambos soportes narrativos. 
Parto de la certeza de que el contexto en que se desarrolla el proceso de adaptación desempeña un rol fundamental y me adhiero al doble criterio apuntado por Carcaud-Macaire y Clerc: "la demande du public et les conditions du "marché' cinématographique" (35). Los casos que aquí analizo permiten suponer dos hechos que corren en forma simultánea: una vez consolidado el cine en México, se altera la forma en la que privilegia la información sobre el autor y el texto literario del cual se desprende la historia contada. También se infieren cambios de orden sociocultural, en los que las estrellas del espectáculo copan el espacio antes reservado para los personajes de la cultura y el arte. Los "critères hérités d'une culture fondée sur la traditionelle prépondérance de l'abstraction intellectuelle et de la rationalité linguistique" ("une idéologie culturaliste") son o bien puestos en suspenso por ciertos segmentos de la sociedad, o bien desplazados por los materiales audiovisuales que se erigen en otra manera de leer (Carcaud-Macaire y Clerc 37, 39).

Finalmente, en este artículo espero proponer algunos visos de respuesta a una pregunta formulada en el trabajo pionero de Carmen PeñaArdid. Cuando sostiene que los escritores no han desdeñado tanto el cine como suele creerse, se interroga sobre la causa por la cual sigue prevaleciendo un imaginario sobre la infravaloración del producto audiovisual en relación con el texto escrito: " $\mathrm{d} E s$ un problema de cantidad o de prestigio, de la influencia cultural que en un cierto momento tuvieran unos y otros?" (42). Peña-Ardid sostiene que estudiar esta cuestión demanda un análisis específico. A este pretendo abocarme.

\section{Asimetrías y jerarquías}

La relevancia del canon de la palabra escrita, así como el peso de la literatura por encima de un nuevo medio, como lo era el cine a principios del siglo XX, son dos argumentos que aparecen de manera repetida, cuando se aborda la relación entre ambos soportes artísticos (Clerc y Carcaud-Macaire; Peña-Ardid; Sánchez Noriega; Wolf). En México, esta situación se manifestó de distintas maneras. Por ejemplo, Alfonso Reyes y Martín Luis Guzmán decidieron firmar como "El Fósforo", para escribir sus reseñas cinematográficas. Ambos, en 1915, eran estimados como grandes promesas de la generación del Ateneo de México. ${ }^{2}$ Quizás

2 Apreciación que se consumó casi de inmediato en Reyes, cuando da a conocer Visión de Anáhuac (1917) y va agrupando su serie Simpatías y diferencias, en los años inmediatos. Una década después, Guzmán publica El águila y la serpiente (1928) y La sombra del caudillo (1929). 
optaron por encubrirse con el seudónimo ante la dubitación del lugar que las proyecciones cinematográficas ocuparían en los años venideros. Deslumbrados por lo que tenían ante sus ojos y lo que los rodeaba (por el hecho cultural que el cine representaba), no se abstrajeron de la seducción de la pantalla grande, pero tampoco se atrevieron a afirmar con contundencia el rol que desempeñaba en el concierto de las artes. Su arrojo, no obstante, se traduce en que, a pesar de que habían transcurrido casi dos décadas desde los primeros visionados en México, solo esta dupla osaba mostrar su interés público por un fenómeno que no era dimensionado como un "asunto digno de las Musas" (Reyes 199). ${ }^{3}$

Las oscilaciones sobre cuál es el estatuto artístico del cine, dice PeñaArdid, continuaron hasta entrados los años setenta. En el caso de la academia, apunta cómo en las historias de la literatura, las múltiples relaciones con el cine apenas si han merecido "notas marginales" (44). Una década más tarde, Gilles Deleuze abona esta percepción: "Tengo la impresión de que las concepciones filosóficas modernas de la imaginación no tienen para nada en cuenta al cine" (3). En ese sentido, casi un cuarto de siglo después, si bien se han incrementado sensiblemente los análisis acerca del tratamiento de los textos literarios en los productos audiovisuales o de la influencia de estos en aquellos, aún hay terrenos menos explorados como el rol de los escritores como guionistas, el lugar del cine en el canon literario o su presencia en las historiografías literarias, por poner algunos ejemplos. ${ }^{4}$

En su comentario sobre los escritos de Reyes acerca del cine, José de la Colina observa con agudeza el acercamiento del regiomontano a las historias: "los comentarios derivan de ver aquel que quizá ya se glorificaba apodándolo 'el Séptimo Arte’ desde el punto de vista del escritor, es decir

3 En realidad, otros escritores mexicanos publicaron sobre el nuevo invento que había llegado a la capital del país a mediados de 1896. El poeta Luis G. Urbina enseguida se refirió a él. También lo harían Amado Nervo, José Juan Tablada, Ángel de Campo, etc. Se le adjudica a Fósforo, no obstante, el "inicio a la crítica cinematográfica en lengua española, sólo que lo harán en Madrid" (González Casanova 52). En México será hasta 1917.

4 Sobre la presencia de las técnicas cinematográficas en la narrativa mexicana puede verse el libro de J. Patrick Duffey. Adriana Sandoval selecciona un corpus de novelas mexicanas llevadas a la pantalla y analiza tanto algunos aspectos contextuales que permitieron su traslado como las operaciones que se ejercieron en el proceso de adaptación. Desde una perspectiva más didáctica, Letras hispánicas en la gran pantalla (Lema-Hincapié y Domènech) aborda la relación entre Pedro Páramo de Juan Rulfo y la versión cinematográfica de Carlos Velo (también otras de autores no mexicanos en producciones mexicanas y a la inversa; es el caso de Cabeza de vaca y El lugar sin límites). La bibliografía más abundante es justo esa, la que se ocupa de adaptaciones específicas. La falta de espacio me impide dar constancia puntual de ellas. 
de los argumentos, y considerándolo una 'musa menor', como el ajedrez". Es decir, no repara en aspectos consustanciales al lenguaje audiovisual y, en cambio, sigue leyendo las obras del cine silente desde ángulos más cercanos a la literatura; en este caso, las tramas y, por lo tanto, en un elemento abstracto, susceptible de ser traspuesto a distintos soportes. Esta tendencia prevalecerá también en la crítica periodística, la cual se centrará en dar a conocer el tema principal y la historia que vertebra el texto fílmico con algunos apuntes ligados a la producción (costos, elencos, vestuarios, escenografías). La puesta en escena aparecerá tan solo para referirse a las interpretaciones. Conforme se va consolidando la industria cinematográfica y el sistema de estrellas en que se cimienta, a lo largo de la época de oro, las reseñas de la prensa persistirán en atender cuestiones cercanas al hecho cinematográfico. ${ }^{5} \mathrm{El}$ hecho fílmico, es decir, los aspectos específicos del texto cinematográfico prácticamente serán ignorados. No extraña, entonces, que en los procesos de adaptación se favorezcan los contenidos y sobre estos se trabajen las imágenes publicitarias del filme; principalmente cuando el texto original es ampliamente conocido.

\section{El viaje de ida: del texto literario al fílmico}

Una de las características predominantes del primer cine sonoro fue su inclinación por trasladar a la pantalla novelas de una centuria atrás (el siglo XIX), denominadas como clásicas y, por lo tanto, que eran identificadas por el público potencial: Clemencia (1869) de Ignacio Manuel Altamirano; La calandria (1891) de Rafael Delgado; dos de las populares novelas de Vicente Riva Palacio: Monja y casada, virgen y mártir y Martín Garatu$z a$ (ambas de 1868), por nombrar las más sobresalientes. ${ }^{6}$ Se continuaba así una tendencia inaugurada desde el segundo periodo del cine silente mexicano, en el que a través de esta estrategia se intentaba legitimar culturalmente una expresión aún no estimada como artística. Gustavo García

5 Trabajados desde la semiología y a partir de los conceptos acuñados por Gilbert CohenSeat, Santos Zunzunegui apunta que el hecho fílmico se refiere a "todos esos elementos que pueden encontrarse como tales en la película como objeto terminado [...] mediante un sistema de combinación de imágenes". El hecho cinematográfico son "todos esos hechos que rodean a la producción de la película, lo que suele llamarse comúnmente 'elementos contextuales" $(52,57)$.

6 En un breve capítulo, Silvia Castillo Ledesma plantea que las novelas mexicanas del siglo XIX adaptadas al primer cine sonoro contribuyeron a consolidar el proyecto nacionalista, traducido en un cine propio hablado en español (869-876). 
identifica un ingrediente más: la atracción de otro tipo de público, menos popular, a las salas de proyección (46). Quien actuó en Santa como El Jarameño (Juan José Martínez Casado) recordaba: "Aquello fue increíble, unos 'llenazos' enormes, fue un éxito; yo que estaba afuera, veía salir a las mujeres llorando; en realidad, la película se hizo para la gente high-life, pero el pueblo fue el que se identificó con ella" (citado en García Riera 50).

Ver en la pantalla "clásicos" de la literatura justificaba la presencia de una audiencia más pudiente en foros que, en un inicio, se acercaban al diseño de las carpas y los teatros, y no a los palacios cinematográficos de los años cuarenta. El razonamiento era similar en cuanto al tema de Santa. Al ser escabroso, su enfoque moralizante fue decisivo para evadir la censura. Las películas se apegaron cada vez más a ese mensaje y ello contribuyó, sin duda, a la atracción que ejercía entre la audiencia. Su estatuto de clásico temprano, en el canon literario, operaba como una suerte de autorización para entrar a ver la historia de una joven ingenua que es engañada y termina en un burdel. De otra forma, la osadía del nuevo medio se habría impregnado de matices negativos que hubieran alejado a los espectadores. Así, "en el origen de las adaptaciones literarias está el barniz intelectual que podían proporcionar a un medio como el cine, necesitado de reconocimiento artístico" (Sánchez Noriega 52).

Señalada como la primera película sonora del cine mexicano, Santa (Antonio Moreno 1932) recibió toda suerte de elogios en la prensa nacional y en ellos pesaba fuertemente el ingrediente de la autoría: Federico Gamboa parecía tener una preponderancia incluso mayor que la del mismo director. ${ }^{7}$ No parece haber sido fruto del azar la selección de esta novela para una producción de tal trascendencia y para la cual se aseguraron de contar con un equipo formado, en su mayoría, en los estudios de Hollywood. Además, el reconocimiento popular del que gozaba Gamboa se remontaba a la adaptación para teatro y zarzuela; pero también a la primera versión cinematográfica (1918), en el marco del cine silente. Según relata Gamboa en su diario, "Sacaron mi retrato en la pantalla y lo aplaudió el público" (citado 
en Pacheco "No vayas a creerme" 216). ${ }^{8}$ El peso del autor en la celebridad del filme silente era inobjetable. Pocos elogiaban el producto audiovisual, pero todos reconocían su triunfo comercial: "Película llena de defectos, mas un gran éxito de taquilla por lo popular que era la novela de don Federico Gamboa", explicaba el director Juan Bustillo Oro al hablar sobre la obra de su colega, Luis G. Peredo (Meyer 44).

Para su segunda puesta en escena (la versión sonora de Antonio Moreno), tanto en los carteles como en los fotomontajes dedicados a la promoción, dentro y fuera de México, se destaca el texto origen de la historia que la película cuenta. En su estreno en el elegante y céntrico cine Palacio, la mención de "Don Federico Gamboa" estaba en primer término. En su siguiente corrida, para atraer al público al cine Royal,justo después del título del filme constaba quién era el autor de la novela. "La inmortal obra de Federico Gamboa", rezaba el impreso que circuló en España, a través de Selecciones Filmófono. Esto no resulta extraño, si se tiene en mente que el mismo Gamboa fue involucrado en el proceso de preproducción del filme y, sobre todo, que era valorado como uno de los principales atractivos de ese proyecto. Así, cuando la ya famosa en Hollywood, Lupita Tovar viene de visita a México y se le convence de protagonizar el filme, se da a conocer un reportaje en donde el escritor pasea con la actriz por el barrio de Chimalistac (punto de arranque de la historia) y le presenta a quien le inspiró a la joven Santa (De la Vega Alfaro). La prensa de la época (El Universal Ilustrado, El Universal Gráfico, La Opinión, Excélsior) subrayará tanto la obra literaria como la autoría de la misma, entre la información brindada sobre el inminente rodaje. En plena producción, la figura del autor continuará en un primer plano:

A la filmación de la película "Santa", acude el autor de la novela, don Federico Gamboa. Y aunque don Federico también ha hecho algunas bilis durante la definitiva adaptación de la obra a la película, puede considerarse feliz. Por dos causas: porque su ojo vigilante controla las expansiones, a veces subversivas del dinamismo sintético de la cinematografía; y porque la película se está desarrollando felizmente, con tal acierto que viene a dar nueva vida a su novela inmortal. Don Federico llega al estudio y se sienta cerca del escenario. Observa callado las escenas: oye, discreto, las observaciones técnicas de Antonio Moreno. (citado en De la Vega Alfaro)

8 Para conocer más sobre el éxito de estas dos primeras versiones cinematográficas en México, en las regiones de habla hispana en Estados Unidos y en Latinoamérica, véase Irwin y Castro Ricalde. 
En esta reseña sobresale uno de los rasgos con que las adaptaciones suelen ser evaluadas: la fidelidad a la obra literaria como condición impuesta al hipertexto resultante. La mirada acechante de Gamboa certificaba que la traición (a la que la narrativa cinematográfica parecería predispuesta) no tuviera grandes repercusiones. Entra también a un juego al que se habían prestado otros autores y era el de incitar al público a ver la película, compararla con la novela y luego emitir su opinión (Sandoval 25).

De aquí que en el material publicitario fuera mencionado el autor, incluso antes que la estrella de Hollywood, protagonista del filme (Lupita Tovar). Seguirá figurando (con menor prominencia) en los carteles de la siguiente versión, estelarizada por Esther Fernández y Ricardo Montalbán, estrenada en 1943. A pesar de que el escritor había fallecido unos años antes, la película se promoverá como “ ¡La apasionante obra de Federico Gamboa!". También es notorio el señalamiento sobre el gran provecho que reportaba el cine a la novela: le daba nueva vida. Así lo cree Piñera Tarque: la "difusión y suerte cinematográfica constituye un fenómeno válido para la constitución y análisis del canon literario dominante" (252), pues puede servir como indicio sobre la vigencia de los autores, las obras o ambos. El hecho de que algunos personajes, a partir de su paso por el escenario, crecieran ante el público (fuera por su villanía, fuera por su bondad) insuflaba un soplo de actualidad al texto literario. ${ }^{9}$

El anclaje en la obra escrita se manifiesta en el filme desde los primeros créditos. Lo que vemos es un libro que se abre y antes de que esto ocurra, la cámara se detiene en la portada del mismo: título y autor son las únicas grafías de ese plano. Ya después, con el correr de las hojas, se presentará el elenco estelar, el director, el adaptador y el resto del cuerpo técnico. Así, "Habría la clara sugerencia, pues, de que la película nos 'leerá' la novela" (Sandoval 28$).{ }^{10}$

9 Así sucede con Hipólito, el poco agradable pianista ciego de la novela, que va idealizándose conforme transcurren las distintas transposiciones a la pantalla. Llegará un momento en el que la creencia popular lo asociará con el súper famoso Agustín Lara (compositor de la música de la segunda edición fílmica), sin importar la evidente anacronía. El personaje crecerá de tal modo que tendrá su propia película, Hipólito, el de Santa (Fernando de Fuentes, 1949), cuyo argumento provendrá de la pluma del hijo de Gamboa, Miguel. Nótese el título y la cita a la novela original.

10 Hernández describe también la aparición de este recurso en el filme de Norman Foster. Aquí, los personajes dibujados en la portada cobran vida (28). Queda claro que su existencia depende de la emanada de las páginas de la narración novelesca. 
Ángel Miquel describe la relevancia que tuvo para el cine de los años veinte la llegada de los jóvenes al periodismo: "una nueva generación de periodistas convencidos de que el cine era un arte remplazó en México a los viejos cronistas del periodo anterior, que por su formación intelectual ligada a las artes tradicionales nunca habían reconocido mayores méritos al cine" (91). Esto implicó una mayor atención a la producción cinematográfica, lo cual se tradujo en notas, entrevistas, reportajes gráficos y reseñas. No obstante, los ojos estaban puestos, sobre todo, en Hollywood.

En la edad de oro destaca el vínculo del cine con la literatura tanto por el número como por "la calidad de las obras literarias adaptadas" (Guerrero Suárez 15). Es preciso resaltar la tendencia a escoger grandes títulos de la literatura iberoamericana y, sobre todo, universal (destacaron las de Rómulo Gallegos y Vicente Blasco Ibáñez, por ejemplo), por encima de las de origen mexicano. ${ }^{11}$ Añadiría también que se adaptan textos de autores vivos (Mariano Azuela, José Rubén Romero, Mauricio Magdaleno), lo cual marca una notoria diferencia, en relación con ese primer cine que opta por obras consagradas de escritores fallecidos del siglo XIX. La inclusión de Gamboa en los reportajes periodísticos previos a la segunda versión cinematográfica apunta hacia la conciencia plena de que el involucramiento del autor entrañaba un conglomerado de significados: respaldaba la validez del producto audiovisual y lo revestía de un aura artística que se transmitía al público espectador. En términos de Daniel Chávez: "Claramente, la transferencia o 'contagio' del capital cultural del campo literario hacia el campo de la producción cinematográfica era lo que los productores de cine buscaban captar" (133).

\section{El viaje de regreso: del texto fílmico al literario}

Nayibe Bermúdez Barrios describe las etapas que atravesó el relato "Miroslava" de Guadalupe Loaeza, publicado originalmente en 1989 como parte del volumen Primero las damas (111-119). El director Alejandro Pelayo lleva al cine en 1993 la adaptación de Vicente Leñero y conserva para su película el título de la narración. La adquisición de los derechos primero y, posteriormente, la notoriedad del filme redundará en que el

11 En ello podría contribuir la reputación de artistas como Alejandro Dumas, Guy de Maupassant, Stefan Zweig u Óscar Wilde, pero también a algo más trivial como que no se "remitía dinero alguno a sus autores en el extranjero" (Peredo Castro 194). Menos si estaban muertos. 
texto unitario es desprendido del volumen original y es publicado en una edición con el nombre de Miroslava por una casa editora diferente (la primera fue Cal y Arena; la segunda, Alianza Editorial). La nueva presentación ya va acompañada por imágenes e incluye una presentación de Carlos Monsiváis, estudios sobre la actriz, su filmografía y una ficha sobre la película de Pelayo. Como señala Bermúdez Barrios, este "nuevo conjunto [...] ejemplifica de manera metafórica, puesto que no se va de un medio de representación a otro, el tipo de transformación y negociación de intertextos, que ha venido a llamarse adaptación" (113).

Si bien los carteles con que fue promovido el filme (y que fueron la base para la cubierta de los dvd que se comercializaron) no destacan a los autores del genotexto (Loaeza y, luego, Leñero), los fotomontajes sí dan cuenta de los mismos. Por otro lado, la imagen central de ambos productos difiere: en el caso de la película, es la actriz Arielle Dombasle y en el de las ediciones posteriores al filme, es una fotografía de la propia Miroslava. Llama la atención el entrecruzamiento de realidad y ficción elegido para promover la narración de Loaeza. Su estatuto de relato literario cobra un interés renovado, tanto por el filme como por el personaje real (la actriz Miroslava Stern), desplegado en la cubierta. Debido al propósito del libro de Bermúdez Barrios, esta señala el peso que se cernía sobre la literatura realizada por mujeres en la década de los noventa (117). Yo añadiría: con el objetivo de consolidar las ventas, solo se afirma la autoría de Loaeza de manera relativa, puesto que aun cuando ella figura como la responsable del volumen en la cubierta del libro, en el interior del mismo su obra se pierde entre los demás materiales. De forma más relevante, esto también ocurre con el género discursivo que da pie a todo el volumen, pues se privilegian las representaciones vinculadas con la persona (fotografías, breve biografía, análisis sobre las películas de Stern y su inserción en el cine mexicano). Así, parecería pasar a un segundo término tanto el personaje literario como el texto escrito que fue el germen de todo este esfuerzo editorial.

En síntesis, este caso es útil para argumentar cómo en el viaje de retorno de la película a la obra literaria, esta es fortalecida no por sus valores intrínsecos sino por aquellos aportados por el endotexto. Se busca atraer a un público lector mediante estrategias diversas que no se relacionan, necesariamente, con los aspectos estéticos del relato de Loaeza. En forma similar, pero con diferencias que lo convierten en otro caso de interés, casi diez años más tarde Marcel Sisniega adapta la novela de Daniel Sada, Una de dos (1994). 
Cuando el autor de Una de dos se incorpora a la difusión de la película dirigida por Sisniega (2002), de alguna manera plantea lo anterior, según se infiere en la siguiente cita, extraída de una nota periodística: "Para Daniel Sada 'es una feliz coincidencia que salga libro y que salga una película al mismo tiempo'. A esto le podemos agregar que para el autor de Porque parece mentira la verdad nunca se sabe, la publicación de Una de dos es un reencuentro con una novela que ya lleva ocho años de vida" (Jhon 40). Como observamos con el caso de Santa, el filme Una de dos funcionó de manera revitalizadora para la narración del oriundo de Baja California. Originalmente publicado por Alfaguara en 1994, con el inminente estreno de la versión audiovisual en 2003, Tusquets lanza de nueva cuenta este texto literario en 2002. Esta es una tendencia, según observa Daniel Chávez: "A partir de la última década del siglo XX ya no es de extrañarse que la première de una adaptación anime a los editores a lanzar ediciones 'asociadas' con cubiertas rediseñadas con referencias explícitas a la versión cinematográfica de la obra anunciando su relación" (133). Así ocurrió con Diarios de motocicleta de Ernesto "Che" Guevara y El búfalo de la noche de Guillermo Arriaga.

$\mathrm{El}$ anuncio de que se llevaría al cine la novela estimularía el interés de la prensa por entrevistar al de Mexicali. Habla de cómo trabajó dos años al lado de Sisniega para convertir la trama en un guion. Pero cada vez que puede introduce evocaciones personales y consideraciones sobre el texto literario. Léase uno de los titulares: "La tradición novelística en México, apenas en construcción: Sada" (Arredondo 21). También esta circunstancia le abrirá las puertas para escribir artículos para la prensa nacional ("Intríngulis fílmico"), en el que se destacará fuera del cuerpo del texto: "La literatura es más compleja que el cine" así como "Con una lista de restricciones y la idea de respetar al máximo su novela, Daniel Sada se estrenó como guionista" (Sada 1).

Daniel Sada ya era un escritor ampliamente conocido entre la comunidad lectora, cuando se anuncia que comenzará el rodaje del filme de Sisniega. Dos lustros antes, había recibido uno de los premios más prestigiados del país, el Xavier Villaurrutia, por uno de sus libros de cuentos (Registro de causantes, 1990). La novela que lo consagró, Porque parece mentira... (1999), fue galardonada con el José Fuentes Mares. En esos mismos años, se generó un interés inusitado por la cultura del norte mexicano. Hubo una entusiasta recepción de autores de esos lares (Patricia Laurent Kullick, David Toscana, Eduardo Antonio Parra, Rossina Conde, Rosario Sanmiguel, Luis Humberto 
Crosthwaite, por mencionar unos pocos); la de grupos musicales y cantantes de gran impacto (Nortec, Control Machete, El Gran Silencio, Tijuana no, Julieta Venegas, por ejemplo), artistas plásticos como Marcos Ramírez Erre e Ivonne Venegas. De ahí la afirmación de Domínguez Michael: "Cierta justicia sociológica se ha impuesto en la imaginación literaria de México y tras Sada, Jesús Gardea, Eduardo Antonio Parra y ese extraño visitante que fue Bolaño, ha sido el norte desértico, violentísimo y a su manera hipermoderno, el escenario de las narraciones más memorables".

Esta atmósfera suscitó una revitalizada atención, fortalecida con los múltiples interrogantes hacia la centralización cultural imperante en el país. De ello se benefició la literatura de Sada, la cual era apreciada por la crítica, aun cuando sus rasgos de estilo (poético, barroco) no propiciaban el encuentro fácil con los lectores no especializados. Una de dos evitó la tentación de una prosa espesa y extensa, presente en parte de la escritura de Sada y, en cambio, en su brevedad concentró muchas de sus virtudes. Revisitar la provincia y conservar sus giros lingüísticos y sus acentos fueron dos de ellas, a través de la historia de las gemelas idénticas que deciden compartir al novio sin que él lo sepa. Tal vez Marcel Sisniega, quien escribió el guion junto con Sada, sospechaba que no iba a ser sencillo levantar ese proyecto cinematográfico, al compararlo con las temáticas de las cintas más atractivas para el público en los años inmediatos: "El éxito casi simultáneo de cintas como Sexo, pudor y lágrimas (Antonio Serrano, 1999), La ley de Herodes (Luis Estrada, 1999), Amores perros (Alejandro González Iñárritu, 2000), Y tu mamá también (Alfonso Cuarón, 2001) y El crimen del Padre Amaro (Carlos Carrera, 2002) alentaron las expectativas del cine mexicano" (Castro Ricalde 15). Sus temáticas urbanas, de relaciones de parejas jóvenes o adolescentes, sexo, violencia o corrupción estaban muy distantes del tono de comedia ranchera que dibuja el vínculo estrecho de las hermanas Constitución y Gloria Gamal, habitantes de un pueblo recóndito.

A pesar de ir a contracorriente del tópico abordado, el género cinematográfico, el reducido número de salas en las que se estrenó, la película Una de dos tuvo una buena recepción crítica. Devolver a los escenarios el entorno provinciano, evocar las comedias de la edad de oro, trabajar los diálogos aparta a la cinta de la tónica (atractiva para los públicos, por demás) de esos años y en ello se fijan los críticos: "En medio de las exitosas, espectaculares y excesivas visiones urbanas de un nuevo cine mexicano de claras aspiraciones mercadotécnicas que arrancó con Sexo, pudor y lágrimas, seguido por cintas como Todo el poder, La segunda noche, De la calle, El segundo aire, Vivir mata y Ciudades oscuras, entre otras, las pantallas nacionales se han 
topado con un inesperado regreso a los temas del campo" (Aviña 2). Una de dos, según se infiere, no es vinculada con esas "aspiraciones mercadotécnicas" y en ello interviene (selección de espacios, lenguaje utilizado, historia), por supuesto, la mano del escritor.

Dos hechos sobresalen: por un lado, la doble estrategia publicitaria, en lo que a la novela de origen se refiere; por el otro, la relevancia de Sada en las múltiples reseñas cinematográficas. En este acercamiento, resaltaré las transformaciones en cuanto al tratamiento autoral; no es la obra literaria la que pesa por sí misma sino su autor. Es decir, lo que está en juego en este proceso, según veremos, no es ya el juicio alrededor de la fidelidad que la película le "debe" al texto escrito; tampoco lo es la jerarquización de un soporte sobre otro. De lo que se trata ahora es de qué tan visible es el escritor, a fin de fortalecer la obra fílmica como producto mercantil (de aquí que, en otros casos de adaptación a películas contemporáneas, el origen de la historia quedará prácticamente borrado). La inscripción cultural del autor se ha modificado, al no atarse la recepción a la lectura, al conocimiento de la obra adaptada, sino al tratamiento de "star" que se le ha concedido mediáticamente.

Para promover la cinta de Sisniega, se optó por alejarse de la solemnidad y aire a antiguo con que se dio a conocer la primera edición de la novela. En su lugar, se presentó una base gráfica del plano medio de una mujer. Dividida la imagen a la mitad y verticalmente, al moverse hacia arriba una, en relación con la otra, y jugar con distintos tonos de azules quedaba clara la presencia de las gemelas. Colores vivos, tipografía juguetona, estilo naïve fueron los principales elementos en los que, además del título, solo aparecían los nombres de las actrices estelares: Tiaré Scanda y Erika de la Llave. ${ }^{12}$ En otra versión, en letras pequeñas y de manera poco destacada en la parte inferior del cartel, se insertaban los nombres de los integrantes de la producción, entre ellos, casi perdido, el de Sada. A diferencia de los carteles de la edad de oro, ${ }^{13}$ los impresos publicitarios ignoraron la fuente primera de la película.

12 De esta dupla, era Tiaré Scanda la más famosa, pues De la Llave apenas había participado en un largometraje. Scanda ya había sido nominada a un Ariel (el máximo galardón de la cinematografía mexicana) por su papel de reparto en El callejón de los milagros (Jorge Fons, 1995). Había trabajado en telenovelas, varias películas y protagonizado otra bajo la dirección de María Novaro (Sin dejar huella, 2000). Sin embargo, al ser la historia de unas mellizas y mostrar en el cartel una imagen ambigua (podría pensarse que se presentaba a una sola persona), la producción apostó por la fama de Tiaré.

13 Puedo ofrecer casos múltiples. Elijo dos representativos: el hermoso cartel de Los de abajo (1940) especifica, en letras de mayor tamaño que las del director Chano Urueta: "Basada en la 
Frente a este silencio contrasta la alharaca de la pre y la posproducción, en cuanto a la integración de Sada a la campaña promocional del filme.

El siguiente hecho, la presencia de Sada, aparecerá en casi toda la prensa nacional desde los titulares: "Comienza la filmación de Una de dos. Dirigida por Marcel Sisniega, protagonizada por Tiaré Scanda y Erika de la Llave y basada en la novela homónima de Daniel Sada" (Dorantes 72). Si bien la politique des auteurs cambió por completo la manera de considerar la dirección cinematográfica y esto es evidente en la mención de Sisniega en primer lugar; si el sistema de estrellas convierte a sus protagonistas en el principal atractivo del filme; la presencia de Sada es destacable. Podemos ver en este proceso lo puntualizado por Deleuze, sobre los "factores históricos y geográficos que atraviesan el cine, que lo relacionan con otras artes, que ocasionan que reciba influencias o que las ejerza" (6). Lo que influyó en la elección de la obra literaria para llevarla a la pantalla no puede ser separado de las imbricaciones sociales, históricas y políticas que dieron pie al texto cinematográfico. Así, hay que tener en la mente que esta promoción ocurre cuando filmes tan populares como los ya mencionados y de directores que estaban despuntando (Serrano, González Iñárritu, Estrada) han despertado la curiosidad por las producciones mexicanas, en un público nacional reticente a aceptarlas. El autor y el origen literario del filme se convierten en elementos diferenciadores que lo apartan del conjunto.

Las reseñas sobre la película provendrán de algunas de las plumas más reconocidas: Jorge Ayala Blanco, Tomás Pérez Turrent, Carlos Bonfil, Rafael Aviña, Andrés de Luna y Ernesto Diezmartínez (entre otros), quienes escribían en los periódicos más destacados de ese momento. Si bien es cierto que el número de filmes mexicanos estrenados en 2012 y 2013 aún era reducido, ${ }^{14}$ sobresale la mención del autor y su estilo, del texto original, del guion escrito

obra del Doctor Mariano Azuela". En un diseño mucho más desorganizado, Pito Pérez (Miguel Contreras Torres, 1944) será aún más explícito: "Basada en la novela de Dn. José Rubén Romero La vida inútil de Pito Pérez".

De acuerdo con datos del Instituto Mexicano de Cinematografía, la producción se vino abajo justamente en 2002. Para que repuntara el siguiente año (cuando se estrena Una de dos), se requirió la intervención decidida del subsidio del gobierno: en 2003, "sólo dos de las diecinueve cintas no fue respaldada por alguna instancia de IMCINE, lo cual no dista demasiado de lo ocurrido en años cercanos: aproximadamente el $85 \%$ de las obras contaron con alguna ayuda estatal" (Castro Ricalde 14). 
al alimón entre el de Mexicali y Sisniega. ${ }^{15}$ El veterano de la crítica cinematográfica Ayala Blanco describirá juguetonamente la intervención de Sada, mediante guiños múltiples a los autores mencionados: "Basado con enorme gracia en la neobarroca novela homónima del cursipóstumo escritor 'excéntrico' (Domínguez Michael dixit) de la literatura mexicana finisecular Daniel Sada [sic], adaptada en colaboración con él mismo, el originalísimo segundo largometraje..." (88). Esta misma cercanía a la obra del escritor es perceptible en la colaboración de Bonfil, quien habla de las atmósferas de sus novelas "y sobre todo su precisión en el registro del habla pintoresca" (4). Y Andrés de Luna podrá discernir qué rasgos del filme provienen de la obra literaria: "bajo la mirada cómica y la ironía de Daniel Sada, aparece el filme "Una de dos"' (9).

Como los demás periodistas, Bonfil elogiará el guion ("se resuelve en una sencillez fílmica poco común en nuestro medio") (4) y esto se traducirá en una nominación al Ariel, en el rubro de adaptación. Otro elemento común entre quienes escriben sobre la película es mencionar a Sada, cada vez que se refieren a la historia: "Sin más pretensión que entretener, Sisniega y Sada narran la historia" (Aviña 2). Diezmartínez añadirá un dato más: "Finalmente, las canciones que se escuchan en la banda sonora, escritas por Sada y su esposa Adriana Jiménez y con música de Santiago Ojeda, resultan ser el complemento perfecto de una película que nunca pierde su amabilidad, su sentido del humor, y su sencilla gracia cómica" (12).

Reconocer la huella de Sada en la cinta de Sisniega habla de, por lo menos, cierto conocimiento del estilo de su escritura. La presencia del autor en las ruedas de prensa, sus propios escritos sobre el proceso de llevar la novela a la pantalla, mencionarlo en las reseñas y detenerse en el guion no forma parte de la norma. Pueden celebrarse las historias, pero el creador de las mismas no es motivo de atención para la prensa. Y mucho menos si sus nombres no se han integrado en el canon de la literatura mexicana o, por lo menos, se avizora que así fuera a ocurrir. Por ejemplo, la uruguayo-mexicana Laura Santullo ha sido reconocida por sus narraciones adaptadas al cine y tres de ellas, filmadas por su marido Rodrigo Plá, han figurado en igual número de Arieles: La zona (2007), La demora (2012) y Un

15 Los ejemplos de escritores literarios que han sido guionistas en México son numerosos. Además de los ya mencionados, es imposible dejar de nombrar a Xavier Villaurrutia, Juan de la Cabada, José Revueltas. Más recientemente, Josefina Vicens, Carlos Fuentes, José Emilio Pacheco, Vicente Leñero. Es mucho menos común el camino inverso: guionistas que se consagran como autores literarios. 
monstruo de mil cabezas (2015). La repercusión de sus libros, en cambio, ha sido menor, por lo que se le identifica más con su escritura cinematográfica en las crónicas que se refieren a las películas mencionadas.

Otro caso es el de Ernesto Alcocer. Después de la cálida acogida de También se llamaba Lola (1993), volvió a publicar en 2007 un volumen de narraciones que contenía una novela corta, "El tercer grado de la obediencia perfecta". El productor Luis Urquiza la leyó, y decidió que ese sería el argumento para su primer largometraje, el cual escribiría con Alcocer y se estrenaría en 2014, con el título Obediencia perfecta. Entre los premios concedidos, estuvo un Ariel en ese renglón. Siguiendo el camino comercial ya descrito, ese año se reeditó el volumen, ahora con el nombre de la película y exhibiendo en la cubierta uno de los fotogramas de la misma. Los méritos de autor, sin embargo, no ocuparon más que algunas menciones y, en cambio, el tema abordado acaparó páginas y páginas de periódicos y revistas. El tópico de los escándalos de pederastia de la iglesia católica fue revivido y, sobre todo, el de las inmoralidades de Marcial Maciel, fundador de la congregación Legión de Cristo en México. Este había fallecido en 2008 aunque en los años inmediatos posteriores continuaron las revelaciones sobre la vergonzosa vida privada del sacerdote. El rodaje y la exhibición del filme avivaron el asunto, lo cual ayudó a una extensa promoción, tal vez opacando el papel desempeñado por Alcocer.

Cierro este artículo matizando la certeza de Peña-Ardid de que se sigue privilegiando la imagen mental emanada de la palabra literaria por encima de la visual que proviene del cine. El autor literario de varias de las películas de la edad de oro ocupa un lugar principal como estrategia de atracción desde la publicidad impresa (carteles, fotomontaje). Más prominente, mientras más conocido o más leída fuera su obra. Si en el nuevo siglo, la figura autoral comparte con el pasado el aura de prestigio artístico que diferencia a un filme de otro - "la garantía de valor" mencionada por Jean Mitry-, esto suele presentarse en un marco de reflexión más amplio (como las reseñas o las entrevistas) y no en los impresos publicitarios.

Si bien se ajusta al caso de Santa, la certeza del éxito comercial esgrimida como una de las razones por las cuales se adapta una obra literaria, no es tal en el caso del cine mexicano contemporáneo. Ante la segmentación de los públicos, la multiplicación de las ofertas de entretenimiento, el reducido número de libros que se leen al año, las novelas que son best sellers no son de origen nacional. Por lo menos, no entran en esta categoría Miroslava, Una de dos u Obediencia perfecta. En las producciones del nuevo siglo, 
sin embargo, más que el nombre del artista de la pluma en sí mismo, pesan las circunstancias que lo actualizan y lo convierten en sujeto de interés para el cine: Guadalupe Loaeza y la escritura de mujeres, a principios de los noventa; el norte y la provincia, a fines de esa década, ofrecen la posibilidad de trasladar la novela de Sada a la pantalla. El caso de Ernesto Alcocer muestra claramente cómo su nombre interesa menos para la comunidad periodística que la temática de pederastia en los círculos eclesiásticos, a raíz del cercano escándalo de uno de sus jerarcas, Marcial Maciel.

Si solo me basara en las narraciones de Loaeza, Sada, Santullo o Alcocer podría sostener que la novedad es uno de los atributos de las adaptaciones del siglo XXI (las cuales no son tan numerosas como se pensaría). Y esto lo ratificaran Escrito en el cuerpo de la noche (Jaime Humberto Hermosillo, 2001), basada en la obra de Emilio Carballido; Demasiado amor (Ernesto Rimoch, 2002) sobre una novela de Sara Sefchovich; Arráncame la vida (Roberto Sneider, 2008) a partir del texto de Ángeles Mastretta, entre otras. En contraposición con Santa, estas historias adaptadas no tienden a idealizar el pasado ni tampoco son condescendientes con el Estado o las restricciones sociales. Por el contrario, tienden a mostrar, a revelar, a acusar, a contribuir a conocer las causas del malestar colectivo existente en México. A pesar de que los subsidios estatales hacen del cine mexicano una realidad, las producciones contemporáneas inspiradas en obras literarias no parecen estar deseosas de complacer a las instancias gubernamentales. En cambio, identifico una cercanía mayor con el mercado y las tendencias del consumo audiovisual, transparentadas en las temáticas escogidas, la exposición de quien escribió el genotexto y las estrategias de cómo se difunde esta información.

Se infiere de las líneas anteriores una mayor dimensión concedida al autor literario, no así a su faceta de guionista; a este no se le asocia aún con el rol del escritor y, por tanto, su función como adaptador se comunica de manera accidental por la crítica periodística, quizás por no constituir un aliciente determinante para la taquilla. Esto tal vez se deba a la incursión meramente incidental de los autores mexicanos contemporáneos en el cine. Por otra parte, la asimetría existente entre ambos campos, el de la literatura y el cine, se presenta con mayor ductilidad, dado cómo se aprovecha el prestigio autoral (los filmes se benefician, pero también la obra literaria que es reeditada). No obstante, que el libro quede indisolublemente ligado a la película, debido a la elección de la cubierta, indica el terreno ganado por las industrias audiovisuales en México. 


\section{Obras citadas}

Arredondo, María Esther. Unomásuno (México, 27 de febrero de 2002): Cultura-21. Impreso.

Aviña, Rafael. "Una de dos". Reforma (México, 19 de enero de 2003): El Ángel-2. Impreso.

Ayala Blanco, Joaquín. "Sisniega y la comedia ranchera naïve". $E l$ Financiero (México, 21 de octubre de 2002): 88. Impreso.

Bermúdez Barrios, Nayibe. Sujetos transnacionales: la negociación en cine y literatura. México: Universidad Autónoma de Ciudad Juárez, 2008. Impreso.

Bonfil, Carlos. "Una de dos". La fornada (México, 27 de abril de 2003): Cultura-4. Impreso.

Carcaud-Macaire, Monique y Jeanne-Marie Clerc. Pour une lecture sociocritique de l'adaptation cinématographique. Montpellier: Éditions du CERS, 1995. Impreso.

Castillo Ledesma, Silvia. "La novela mexicana del siglo XIX y el cine de los años treinta". La lengua española y los medios de comunicación. Tomo II. México: SEP - Instituto Cervantes - Siglo XXI. 869-876. Impreso.

Castro Ricalde, Maricruz. "Transnacionalización y género en el cine mexicano del siglo XXI". Miradas del cine actual. Transnacionalidad, literatura y género. Coords. Juan Carlos Vargas y Guadalupe Mercado. México: Universidad de Guadalajara, 2014. 11-39. Impreso.

Chávez, Daniel. "Escribir novelas como escribir películas. Adaptación, capital cultural y culturas de producción transnacional en el cine de Guillermo Arriaga". Miradas del cine actual. Transnacionalidad, literatura y género. Coords. Juan Carlos Vargas y Guadalupe Mercado. México: Universidad de Guadalajara, 2014. 119-156. Impreso.

Clerc, Jeanne-Marie y Monique Carcaud-Macaire. L'adaptation cinématographique et littéraire. Paris: Klincksieck, 2004. Impreso.

Colina, José de la. "Fósforo". Letras Libres (31 de enero de 2010). http://www. letraslibres.com/mexico-espana/fosforo. Web. 12 de febrero de 2017.

Dávalos Orozco, Federico. "El cine mexicano en 1920". Revista de la Universidad de México 9-10 (México, mayo-junio de 1979): 78-81. Impreso.

Deleuze, Gilles. Negociaciones sobre Historia del cine. Valencia: Episteme, 1996. Impreso.

Diezmartínez, Ernesto. "Sencilla y amable". Reforma (México, 25 de abril de 2003): Primera fila-12. Impreso.

Domínguez Michael, Cristopher. "Casi nunca, de Daniel Sada". Letras Libres (31 de enero de 2009). http://www.letraslibres.com/mexico-espana/ libros/casi-nunca-daniel-sada. Web. 12 de diciembre de 2016.

Dorantes, Jorge. "Comienza la filmación de Una de dos". El Economista (México, 31 de octubre de 2000): 72. Impreso. 
Duffey, J. Patrick. De la pantalla al texto. La influencia del cine en la narrativa mexicana del siglo veinte. México: UNAM, 1996. Impreso.

García, Gustavo. El cine mudo mexicano. México: SEP Martín Casillas Editores, 1982. Impreso.

García Riera, Emilio. Historia documental del cine mexicano. Tomo I. México: Cal y Arena - Universidad de Guadalajara, 1992. Impreso.

González Casanova, Miguel. Los escritores mexicanos y los inicios del cine. México: UNAM - El Colegio de Sinaloa, 1995. Impreso.

Guerrero Suárez, Jorge. El cine sonoro mexicano. Sus inicios (19301937). México: Cineteca Nacional, 1978. Impreso.

Irwin, Robert y Maricruz Castro Ricalde. Global Mexican Cinema. Its Golden Age. London: Palgrave MacMillan - British Film Institute, 2013. Impreso.

Jhon, Luis. "Una de dos, dos mujeres idénticas, dos obras no tanto". El Economista (México, 4 de marzo de 2002): La Plaza, 40-41. Impreso.

Lema-Hincapié, Andrés y Conchita Domènech. Letras hispánicas en la gran pantalla. London: Routledge, 2017. Kindle.

Loaeza, Guadalupe. Miroslava. $3^{\mathrm{a}}$ ed. México: Alianza Editorial, 1994. Impreso.

Luna, Andrés de. "Reduce su historia a simple anécdota". El Universal (México, 9 de mayo de 2003): 9. Impreso.

Meyer, Eugenia, coord. "Juan Bustillo Oro". Cuadernos de la Cineteca Nacional. Testimonios para la historia del cine mexicano. México: Cineteca Nacional, 1976. Impreso.

Miquel, Ángel. Acercamientos al cine silente mexicano. Cuernavaca: UAEM, 2005. Impreso.

Miroslava. Dir. Alejandro Pelayo. Aries Films, IMCINE, Tabasco Films, 1993. Filme.

Obediencia perfecta. Dir. Luis Urquiza. Astillero Films, Producciones Mestizo, 2014. Filme.

Pacheco, José Emilio. "No vayas a creerme santa porque me llamo asî". Proceso (18 de diciembre de 1976). https://www.proceso.com.mx/2591/no-vayasa-creerme-santa-porque-me-llamo-asi. Web. 7 de enero de 2017.

Peña-Ardid, Carmen. Literatura y cine. Una aproximación comparativa. Madrid: Cátedra, 1992. Impreso.

Peredo Castro, Francisco. Cine y propaganda para Latinoamérica. México y Estados Unidos en la encrucijada de los años cuarenta. México: UNAM, 2004. Impreso.

Piñera Tarque, Ismael. "Palacio Valdés en la encrucijada metodológica de la adaptación cinematográfica". Alicante: Biblioteca Virtual Miguel de Cervantes, 2009. 245-282. PDF. 
Reyes, Alfonso. "El cine". Obras completas. T. IV. 1 a reimp.

México: FCE, 1980. 197-236. Impreso.

Sada, Daniel. "Intríngulis fílmico". Reforma (México, 19

de enero de 2003): El Ángel-1-2. Impreso.

Sandoval, Adriana. De la literatura al cine. Versiones fílmicas de novelas mexicanas. México: UNAM, 2005. Impreso.

Sánchez Noriega, José Luis. De la literatura al cine. Teoría y análisis de la adaptación. Barcelona: Paidós, 2000. Impreso.

Una de dos. Dir. Marcel Sisniega. Astrolabio, Imcine, 2002. Filme.

Vázquez Mantecón, Álvaro. "Los orígenes de Santa y la biografía de un calavera". Revista de la Universidad de México 609 (México, marzo de 2002): 39-48. Impreso.

Vega Alfaro, Eduardo de la. "La contribución de Antonio Moreno en la génesis de la cultura cinematográfica en México". Corre Cámara (3 de octubre de 2014). http://correcamara.com.mx/inicio/int. php?mod=noticias_detalle\&id_noticia $=4941$. Web. 11 de enero de 2017.

Wolf, Sergio. Cine/Literatura. Ritos de pasaje. $2^{\mathrm{a}}$ reimp. Barcelona: Paidós, 2004. Impreso.

Zunzunegui, Santos. "Acerca del análisis fílmico: el estado de las cosas". Comunicar. Revista Científica de Comunicación y Educación XV.29 (España, 2007): 51-57. Impreso. 